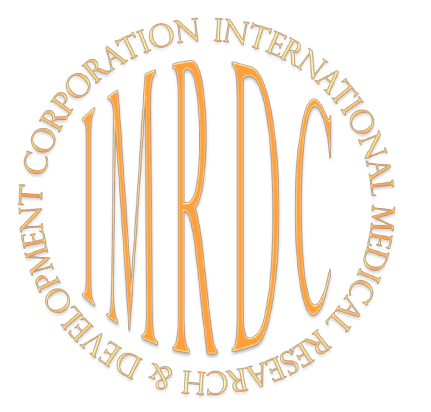

\title{
Preperitoneal Blockade in the Treatment of Patients with Perforated Gastroduodenal Ulcers and Peritonitis
}

\author{
Alexei L. Charyshkin, PhD, ScD*; Sergei A. Yakovlev; Vladimir P. Demin \\ Institute of Medicine, Ecology and Physical Education of Ulyanovsk State University \\ Ulyanovsk, the Russian Federation
}

\begin{abstract}
The objective of this study was to improve the results of surgical treatment for patients with perforated gastroduodenal ulcers and peritonitis (PGDU-P) by applying the preperitoneal blockade.

Materials and Methods: The study included 102 patients with perforated gastroduodenal ulcers (PGDU) complicated by peritonitis. Patients between 18 and 30 years were predominant. Pain was measured using the Visual Analog Scale (VAS) for Pain. The measurements of intra-abdominal pressure (IAP) by indirect infravesical tensometry were performed daily from the first day after the operation. Surgical interventions (laparotomy, laparoscopic suturing of PGDU, sanitation and drainage of the abdominal cavity) was performed under endotracheal anesthesia in all patients.

Patients were divided into two groups depending on the method of postoperative analgesia. Patients of Group 1 (n=62) were subjected only to systemic opioid analgesia (an intramuscular injection of $1 \%$ solution of Promedol $1 \mathrm{ml} 4$ times a day). Patients of Group 2 were subjected to systemic opioid analgesia and catheterization of the preperitoneal space for infusion of $0.5 \%$ solution of Novocaine in the postoperative period.

Results: Postoperative analgesia using preperitoneal blockade after laparotomy and suturing of perforated gastroduodenal ulcers reduced the pain intensity by 2 times in comparison with conventional analgesia. The preperitoneal blockade after laparotomy in PGDU-P patients promotes the effective reduction of intra-abdominal hypertension (IAH) for 2 days. The comparative evaluation of the incidence of the early postoperative complications showed that using preperitoneal blockade contributed to significantly reducing the complications in Group 2. Postoperative mortality was $1.6 \%$ in Group 1 and 0 in Group 2. The average length of stay was reduced by approximately 3 days in Group 2 compared to traditional anesthesia. (Int J Biomed. 2016;6(2):114-118.).
\end{abstract}

Key Words: laparotomy • perforated gastroduodenal ulcers • peritonitis • preperitoneal blockade

\section{Introduction}

In the Russian Federation, the number of patients with complicated peptic ulcer disease (PUD) shows no tendency to decrease. The incidence of perforated gastroduodenal ulcers (PGDU) ranges from $4 \%$ to $30 \%$, and the mortality rate is between $5 \%$ and $18 \% \cdot{ }^{[1-5]}$ Annually, the number of patients who need surgical intervention for PUD complicated by perforation is about 7.5 to13 per 100,000 adult population. ${ }^{[1,2,6]}$ Mortality in PUD patients in Russia is 30,000 or more people per year; the temporary disability after surgery is between 30 and 45 days. ${ }^{[1,2]}$

*Corresponding author: Prof. Alexei L. Charyshkin, PhD. ScD, Head of the Faculty Surgery Department, Institute of Medicine, Ecology and Physical Education of the Ulyanovsk State University. Ulyanovsk, the Russian Federation.E-mail: charyshkin@yandex.ru
Despite the widespread adoption of minimally invasive technologies in the surgery of perforated peptic ulcer disease with peritonitis, laparotomy remains the most common prompt access. ${ }^{[1,2,6,7]}$ Laparotomy and surgical procedures in the abdomen are accompanied by traumatization of the abdominal muscles and peritoneum (the richly innervated tissues), which leads to a marked pain syndrome in the postoperative period. Pain triggers physiological responses that negatively affect the functioning of the organs and systems, with development of several pathophysiologic repercussions, such as prolonged paralytic ileus. ${ }^{[6-12]}$

Traditional analgesia with the most commonly used opioid analgesics is often accompanied by side effects and worsens the postoperative period. ${ }^{[1,2,6,10,12]}$ Currently, some authors consider catheterizing the surgical wound by infusing local anesthetics in the preperitoneal space as the most effective pain relief after laparotomy. ${ }^{[6,8-13]}$ The foregoing 
indicates the need for further studies of the postoperative analgesia for patients with PGDU and peritonitis (PGDU-P) after laparotomy.

The main objective of our study was to improve the results of surgical treatment for patients with PGDU-P by applying the preperitoneal blockade.

\section{Materials and Methods}

The retrospective study was performed in the period from 2001 to 2015. The number of patients for primary selection was 190; the number of patients included in the subsequent analysis was 102 .

One hundred and ninety patients with PGDU-P, aged from 18 to 74 years, underwent laparotomy, laparoscopic suturing of PGDU, and sanitation and drainage of the abdominal cavity in the surgical departments at the Ulyanovsk Regional Clinical Center of Specialized Types of Medical Aid in the period from 2001 to 2015.

Inclusion criteria were age 18 years and older, male and female, perforated pyloroduodenal peptic ulcer, laparotomy, PUD history up to 3 years, the reactive and toxic stage of peritonitis. Exclusion criteria were videolaparoscopy, perforated pyloroduodenal combined with concomitant ulcerogenic complications, toxic and terminal stage of peritonitis, cancer, myocardial infarction, and acute cerebrovascular accident.

This study included 102 patients $(100 / 98 \%$ men and 2/2\% women) with PGDU-P (Table 1). Patients between 18 and 30 years were predominant. All patients were admitted to hospital with duration of perforation between 12 and 16 hours before admission. Standard examination included general clinical, laboratory and special instrumental investigations (X-ray, endoscopy, ultrasound, video-endoscope, histological research methods). Pain was measured using the Visual Analog Scale (VAS) for Pain. The laboratory examination included the complete blood count, blood chemistry, urine diastase. Leukocyte intoxication index (LII) was calculated according to V. K. Ostrovsky (1983).

\section{Table 1.}

Demographic characteristics of patients enrolled in this study $(n=102)$

\begin{tabular}{|l|c|c|c|}
\hline \multirow{2}{*}{ Age $(y)$} & \multicolumn{2}{|c|}{ Gender } & \multirow{2}{*}{ Number of patients } \\
\cline { 2 - 3 } & Male & Female & \\
\hline $18-30$ & $38(37.3 \%)$ & $2(2 \%)$ & $40(39.3 \%)$ \\
\hline $31-40$ & $29(28.4 \%)$ & - & $29(28.4 \%)$ \\
\hline $41-50$ & $18(17.6 \%)$ & - & $18(17.6 \%)$ \\
\hline $51-60$ & $12(11.8 \%)$ & - & $12(11.8 \%)$ \\
\hline$>60$ & $3(2.9 \%)$ & - & $3(2.9 \%)$ \\
\hline Total & $100(98 \%)$ & $2(2 \%)$ & $102(100 \%)$ \\
\hline
\end{tabular}

The measurements of intra-abdominal pressure (IAP) by indirect infravesical tensometry were performed daily from the first day after the operation. Measurements were performed in $\mathrm{cm} \mathrm{H}_{2} \mathrm{O}$ and converted to $\mathrm{mmHg}(1 \mathrm{mmHg}=1.36 \mathrm{cmH} 2 \mathrm{O})$.
Intra-abdominal hypertension (IAH) was identified at IAP greater than $12 \mathrm{mmHg}$. According to M. Sugrue and K. M. Hillman (1998), ${ }^{[14]}$ IAH was identified at IAP greater than 12 mmHg.

Surgical interventions (laparotomy, laparoscopic suturing of PGDU, sanitation and drainage of the abdominal cavity) was performed under endotracheal anesthesia in all patients.

Patients were divided into two groups depending on the method of postoperative analgesia. Patients of Group 1 $(n=62)$ were subjected only to systemic opioid analgesia (an intramuscular injection of $1 \%$ solution of Promedol $1 \mathrm{ml} 4$ times a day). Patients of Group 2 were subjected to systemic opioid analgesia and catheterization of the preperitoneal space for infusion of $0.5 \%$ solution of Novocaine in the postoperative period.

The method was performed as follows: Before suturing of laparotomic wound, we formed tunnels in the preperitoneal space along the full length of the laparotomic wound left and right at a distance of 1.5-2.0 $\mathrm{cm}$ from its edges. In the left and right tunnels, plastic catheters with a few holes were inserted. The cannula (the external opening) of the catheter was fixed on the anterior abdominal wall. The catheters were fixed to the peritoneum using absorbable suture material. In the postoperative period, a $0.5 \%$ solution of Novocaine was injected through catheters for pain relief every 3 hours for 3 days (RF patent №2400259; a priority from 02.17.2009). ${ }^{[13]}$

During the postoperative period, adequate fluid resuscitation was performed. Correction of water-salt balance was carried out under the control of the content of potassium, calcium, and sodium in the blood plasma. For parenteral nutrition, protein hydrolysates and glucose-insulin-potassium mixture were administered.

Nasogastric tube was left in place for at least $24 \mathrm{~h}$ after surgery. Prophylaxis and treatment of intestinal paresis was performed by administration of neostigmine methylsulfate ( $1 \mathrm{ml}$ of $0.05 \%$ solution subcutaneously 2 times a day) and hypertonic solution of sodium chloride (60-80 $\mathrm{ml}$ intravenously 1-2 times a day). In order to prevent septic complications, we administered intravenously third-generation cephalosporins.

The study was conducted in accordance with ethical principles of the Declaration of Helsinki. It was approved by the by Ethics Committee at the Ulyanovsk Regional Clinical Center of Specialized Types of Medical Aid. Written informed consent was obtained from all participants.

Statistical analysis was performed using the statistical software «Statistica». (v6.0, StatSoft, USA). Group comparisons with respect to categorical variables are performed using chi-square tests with the Yates' correction or, alternatively, Fisher's exact test when expected cell counts were less than 5. A probability value of $P<0.05$ was considered statistically significant.

\section{Results}

In assessing the effectiveness of preperitoneal blockade, a high degree of pain relief was found in the patients of Group 2 (3.3 \pm 0.4 points) (Tab. 2). Postoperative analgesia 
using preperitoneal blockade after laparotomy and suturing of perforated gastroduodenal ulcers reduced the pain intensity by 2 times in comparison with conventional analgesia.

Table 2.

Total pain scores by Visual Analog Scale for Pain

\begin{tabular}{|l|c|c|}
\hline \multicolumn{1}{|c|}{ Variable } & Group 1 $(\mathrm{n}=62)$ & Group 2 $(\mathrm{n}=40)$ \\
\hline VAS, score & $6.8 \pm 0.5$ & $3.3 \pm 0.4^{*}$ \\
\hline
\end{tabular}

$* P$-value $<0.05$ between Groups

IAH was detected in all patients in both groups starting from the third postoperative day. According to IAH severity, patients were distributed as follows: In Group 1, Grades I, II and III of IAH were determined in $18(29 \%), 36(58.1 \%)$, and $8(12.9 \%)$ of patients, respectively. In Group 2, IAH Grades I and II were detected in $28(70 \%)$ and $12(30 \%)$ of patients; we did not observed IAH Grade III in this Group (Tab. 3).

Table 3.

Distribution of patients by degree of intra-abdominal hypertension

\begin{tabular}{|c|c|c|c|}
\hline Grade & $\begin{array}{c}\text { Group 1(n=62) } \\
(\mathrm{n} / \%)\end{array}$ & $\begin{array}{c}\text { Group 2 }(\mathrm{n}=40) \\
(\mathrm{n} / \%)\end{array}$ & P-value \\
\hline I & $18 / 29$ & $28 / 70$ & $<0.001$ \\
\hline II & $36 / 58.1$ & $12 / 30$ & $<0.01$ \\
\hline III & $8 / 12.9$ & - & $<0.05$ \\
\hline IV & - & - & \\
\hline
\end{tabular}

In patients with IAH Grades II and III (Group 1), the level of IAP decreased from $19.9 \pm 0.3 \mathrm{mmHg}$ (the 3rd day) to $15.3 \pm 0.2 \mathrm{mmHg}$ (the 6th day) and from $22.3 \pm 0.4 \mathrm{mmHg}$ (the 3rd day) to $17.4 \pm 0.4 \mathrm{mmHg}$ (the 7 th day), respectively $(\mathrm{p}<0.05)$. In Group 2, we observed a significant decrease in the IAP level in patients with IAH Grades I and II from 14.8 \pm 0.2 $\mathrm{mmHg}$ (the 3rd day) to $12.1 \pm 0.3 \mathrm{mmHg}$ (the 5 th day) and from $19.4 \pm 0.3 \mathrm{mmHg}$ (the $3 \mathrm{rd}$ day) to $15.1 \pm 0.2 \mathrm{mmHg}$ (the 5 th day), respectively $(\mathrm{p}<0.05)$. The preperitoneal blockade after laparotomy in PGDU-P patients reduced the IAP level by $2.7 \mathrm{mmHg}$ at IAH Grade I and by $4.3 \mathrm{mmHg}$ at Grade II for 2 days.

In Group 1, the first bowel movement (the first stool) we observed was at day $6.5 \pm 0.3$, in Group $2-$ at day $4.2 \pm 0.2$. On the 2nd day of intervention, LII was $10.4 \pm 0.3 \mathrm{CU}$ in Group 1 (Table 4) and 8.1 $\pm 0.2 \mathrm{CU}$ in Group $2(\mathrm{p}<0.05)$; at the 6th day, LII was also significantly lower in Group 2 than in Group 1; by the 10th day, LII was within normal range in all patients.

Table 4.

Dynamics of LII in the postoperative period

\begin{tabular}{|l|c|c|c|}
\hline \multirow{2}{*}{ Group } & \multicolumn{3}{|c|}{ LII $(\mathrm{CU})$} \\
\cline { 2 - 4 } & The $2^{\text {nd }}$ day & The $6^{\text {th }}$ day & The $10^{\text {th }}$ day \\
\hline Group 1 $(\mathrm{n}=62)$ & $10.4 \pm 0.3$ & $8.2 \pm 0.3^{*}$ & $2.3 \pm 0.2^{*}$ \\
\hline Group 2 $(\mathrm{n}=40)$ & $8.1 \pm 0.2^{\wedge}$ & $6.0 \pm 0.2^{*} \wedge$ & $2.2 \pm 0.2^{*}$ \\
\hline
\end{tabular}

$* P-$ value $<0.05$ versus the initial data

$\wedge$-value $<0.05$ between groups
Thus, the superior efficiency of preperitoneal blockade was confirmed by significant differences between two Groups in the severity of intra-abdominal hypertension and time of data normalization.

The number of the early postoperative complications in Groups was as follows: gastrostasis was detected in $34(54.8 \%)$ patients in Group 1 and 16(40\%) patients in Group 2; dynamic ileus in 25(40.3\%) of patients in Group 1 and $12(30 \%)$ patients in Group 2; mechanical ileus (early adhesive disease of the abdominal cavity) in $1(1.6 \%)$ patient in Group 1 (relaparotomy was performed), this complication we did not observed in Group 2; pneumonia - in 10(16.1\%) patients in Group 1 and 2(5\%) patients in Group 2; seroma and suppuration of postoperative wound - in 14(22.6\%) patients in Group 1 and 3(7.5\%) patients in Group 2; thromboembolism and acute cardiovascular failure were identified only in one patient (1.6\%) in Group 1 (Tab. 5).

Table 5.

Early postoperative complications in PGDU-P patients

\begin{tabular}{|l|c|c|c|}
\hline \multicolumn{1}{|c|}{$\begin{array}{c}\text { Early postoperative } \\
\text { complications }\end{array}$} & $\begin{array}{c}\text { Group 1 } \\
(\mathrm{n} / \%)\end{array}$ & $\begin{array}{c}\text { Group 2 } \\
(\mathrm{n} / \%)\end{array}$ & P-value \\
\hline Gastroptosis & $34 / 54.8$ & $16 / 40$ & $>0.05$ \\
\hline Dynamic ileus & $25 / 40.3$ & $12 / 30$ & $>0.05$ \\
\hline $\begin{array}{l}\text { Mechanical ileus (early adhesive } \\
\text { disease of the abdominal cavity) }\end{array}$ & $1 / 1.6$ & - & \\
\hline Pneumonia & $10 / 16.1$ & $2 / 5$ & $>0.05$ \\
\hline $\begin{array}{l}\text { Thromboembolism and acute } \\
\text { cardiovascular failure }\end{array}$ & $1 / 1.6$ & - & \\
\hline $\begin{array}{l}\text { Infected seroma or suppuration } \\
\text { of postoperative wound }\end{array}$ & $14 / 22.6$ & $3 / 7.5$ & $<0.05$ \\
\hline
\end{tabular}

The comparative evaluation of the incidence of the early postoperative complications showed that using preperitoneal blockade contributed to significantly reducing the complications in Group 2. Postoperative mortality was $1.6 \%$ in Group 1. Thromboembolism and acute cardiovascular failure was the cause of postoperative mortality in $1(1.6 \%)$ patients in Group 1. In Group 2, postoperative mortality was absent.

The duration of hospital treatment was $14.5 \pm 0.3$ days in Group 1 and $11.2 \pm 0.2$ days in Group $2(P<0.05)$; the average length of stay was reduced by approximately 3 days compared to traditional anesthesia.

\section{Discussion}

Traditional laparotomy in patients with perforated gastroduodenal ulcers and peritonitis contributes to the longterm pain syndrome in the postoperative period, which disrupts the function of many organs and systems. ${ }^{[1,2,6,10,11]}$ Pain that occurs after surgery has visceral and somatic components. $[1,2,6,10,13]$ Somatic pain after laparotomy is determined by the direct traumatization of tissue during surgical access. It is known that chronic stimulation of spinal afferents from visceral organs may elicit pain, hyperalgesia and allodynia in the 
referred zones of the deep somatic tissues (skin, subcutaneous tissue, muscles and fascia). ${ }^{\left[{ }^{15]}\right.}$ Reduced visceral pain signaling within the spinal cord has been shown to reciprocally diminish cutaneous sensitization. ${ }^{[16]}$

Nociceptive pain is caused by irritation of nociceptors in the parietal peritoneum. ${ }^{[1,2,6,10,13]} \mathrm{T}$. Brennan et al. showed ${ }^{[17]}$ that the blockade of parietal afferents may reduce spinal dorsal horn neuron sensitization thereby providing postoperative analgesia that outlasts the duration of wound infusion. Furthermore, animal studies have shown that parietal pain may sensitize neurons in the spinal cord to visceral colonic pain. ${ }^{[18-19]}$ This sensitization most likely reflects convergence of afferent information from the gut and somatic system within the spinal cord (heterosynaptic facilitation). ${ }^{[20]}$ Thus, the peritoneum and the deep muscular layer play a crucial role in the pain induced by abdominal incisions. This assumption is further supported by the failure of epidural analgesia when metameric level is not high enough to block peritoneal nociceptive influx, even after lower abdominal surgery. ${ }^{[21]}$

Therefore, it cannot be excluded that blockade of parietal pain influx may even contribute to a reduction of the visceral component of pain..$^{[22]}$ The preperitoneal infusion of ropivacaine has recently been shown to prevent mechanical and visceral sensitivity following laparotomy in an animal model. High-dose ropivacaine administered via a preperitoneal infusion or systemic boluses had the same effect on mechanical and visceral sensitivity after laparotomy. ${ }^{[23]}$ According to Beaussier $\mathrm{M}$ et al., ${ }^{[22]}$ preperitoneal continuous infiltration of $0.2 \%$ ropivacaine at $10 \mathrm{ml} / \mathrm{h}$ during $48 \mathrm{~h}$ was an effective method to relieve pain after open colorectal surgery. It reduced morphine consumption and accelerated the postoperative recovery.

Time to ileus resolution after abdominal surgery is one of the most important factors contributing to the duration of hospital stay. A number of pathogenic mechanisms have been proposed for postoperative Ileus. ${ }^{[24-25]}$ Earlier resolution of postoperative ileus has been reported in studies of continuous local anaesthetic wound infusion. ${ }^{[22,26,27]}$

Our results show that the introduction of $0.5 \%$ solution of Novocaine in the preperitoneal space after laparotomy in PGDU-P patients promotes blocking the parietal and tissue pain receptors, which ensures a high degree of pain relief. We believe that the significant decrease in the number of such early postoperative complications as a dynamic ileus and wound inflamations is associated with adequate anesthesia during preperitoneal blockade. In agreement with other reports on continuous local anesthetic wound perfusion, no local complications were observed. ${ }^{[22,28]}$

\section{Conclusion}

Postoperative analgesia using preperitoneal blockade after laparotomy and suturing of perforated gastroduodenal ulcers reduced the pain intensity by 2 times in comparison with conventional analgesia. The preperitoneal blockade after laparotomy in PGDU-P patients promotes the effective reduction of IAH for 2 days.

\section{Competing interests}

The authors declare that they have no competing interests.

\section{References}

1. Ovechkin AM, Morozov DV, ZharkovIP. Analgesia and sedation in the postoperative period: realities and opportunities. Vest Intensiv Terapii. 2001; 4:47-60.[Article in Russian].

2. Ovechkin AM Post-operative pain sybrome: clinical and pathophysiological significance and perspective directions of therapy. Khirurgiia. 2005;6:7-9. [Article in Russian].

3. Karimian F, Aminian A, Lebaschi AH, Mirsharifi R, Alibakhshi A. Perforated Peptic Ulcer, Comparison Between Laparoscopic and Open Repair. Shiraz E-Medical Journal. $2009 ; 10(1): 20-4$.

4. Saber A. Perforated Duodenal Ulcer in High Risk Patients. In: Jianyuan Chai, editor. Peptic Ulcer Diseas. China: InTech; 2011:271-84.

5. Tayeb M, Khan FM, Rauf F. Situs inversus totalis with perforated duodenal ulcer: a case report. J Med Case Rep. 2011; 5:279

6. Raimes SA, Delvin HB. Perforated duodenal ulcer. Br J Surg. 1987; 74(2):81-2.

7. Oribabor FO, Adebayo BO, Aladesanmi T, Akinola DO. Perforated duodenal ulcer; management in a resource poor, semi-urban Nigerian hospital. Niger J Surg.2013;19(1):13-5.

8. Vavrinchuk CA, Kosenko PM Chernyshov DS. Modern aspects of surgical treatment of perforated duodenal ulcer. Khabarovsk: Izdat. IPKSZ, 2013. [Manual in Russian].

9. Krylov N, Vinnichuk D. Perforated ulcer: pathomorphosis, conflicts and trends. Vrach. 2012; 1:15-20. [Article in Russian]

10. Uvarov DN, Levin AV, Antipin EE, Kapanadze LG, Zemtsovsky LYa, Nesterenko SE et al. Efficacy and safety of operation wound infiltration with local anesthetics after lower abdominal interventions. Regionarnaya anesteziya i lechenie ostroy boli. 2008; 2(4): 21-7. [Article in Russian]

11. Charyshkin AL. Patent of the Russian Federation, "Method of preperitoneal blocade in post-operation period". (RU \# 2400259; priority of 17.02.2009, register. of 27.09.2010; Bull \#27). [in Russian]

12. Grundmann RT, Petersen M, Lippert H, Meyer F. The acute (surgical) abdomen - epidemiology, diagnosis and general principles of management. Z Gastroenterol. 2010 Jun;48(6):696-706. [Article in German].

13. Charyshkin AL, SA Yakovlev, Bekin VY Preperitoneal blockade in patients undergoing laparotomy. Vest Eksp I Klin Khir. 2011; 4(2):354-5. [Article in Russian]

14. Sugrue M, Hillman KM. Intra-Abdominal Hypertension and Intensive Care. In: Prof. Jean-Louis Vincent, editor. Yearbook of Intensive Care and Emergency Medicine. Springer-Verlag Berlin Heidberg; 1998:667-76.

15. Janig W, Habler H-J. Visceral-autonomic integration. In: Gebhart GF (ed), Visceral Pain. Progress in Pain Research and Management, Vol 5. Seattle: IASP Press; 1995:311-48.

16. Bueno L, Fioramonti J. Visceral perception: inflammatory and non-inflammatory mediators. Gut 2002;51(Suppl 1):i19-23.

17. Brennan TJ, Zahn PK, Pogatski-Zahn EM. Mechanisms of incision pain. Anesthesiol Clin North America. 2005;23(1):1-20.

18. Peles S, Miranda A, Shaker R, Sengupta JN. Acute 
nociceptive somatic stimulus sensitizes neurones in the spinal cord to colonic distension in the rat. J Physiol. 2004; 560(Pt1):291-302

19. Miranda A, Peles S, Rudolph C, Shaker R, Sengupta JN. Altered visceral sensation in response to somatic pain in the rat. Gastroenterology. 2004;126(4):1082-9.

20. Bielefeldt K, Christianson JA, Davis BM. Basic and clinical aspects of visceral sensation: transmission in the CNS. Neurogastroenterol Motil. 2005;17(4):488-99.

21. Scott AM, Starling JR, Ruscher AE, DeLessio ST, Harms BA. Thoracic versus lumbar epidural anesthesia's effect on pain control and ileus resolution after restorative proctocolectomy. Surgery. 1996; 120(4):688-95.

22. Beaussier M, El'Ayoubi H, Schiffer E, Rollin M, Parc Y, Mazoit JX, Continuous preperitoneal infusion of ropivacaine provides effective analgesia and accelerates recovery after colorectal surgery: a randomized, double-blind, placebocontrolled study. Anesthesiology. 2007;107(3):461-8.

23. Kfoury T, Mazoit JX, Schumacher M, Benhamou D, Beloeil $\mathrm{H}$. A comparison of different dosages of a continuous preperitoneal infusion and systemic administration of ropivacaine after laparotomy in rats. Anesth Analg. 2011;113(3):617-25

24. Holte K, Kehlet H. Postoperative ileus: a preventable event. Br J Surg. 2000;87(11):1480-93.

25. Livingston EH, Passaro EP Jr. Postoperative ileus. Dig Dis Sci. 1990;35(1):121-32.

26. Polgase AL, McMurrick PJ, Simpson PJ, Wale RJ, Carne PW, Johnson W, et al. Continuous wound infusion of local anesthetic for the control of pain after elective abdominal colorectal surgery. Dis Colon Rectum. 2007;50(12):2158-67.

27. Wang LW, Wong SW, Crowe PJ, Khor KE, Jastrzab G, Parasyn AD, Walsh WR. Wound infusion with local anaesthesia after laparotomy: a randomized controlled trial. ANZ J Surg. 2010;80(11):794-801.

28. Liu S, Richman J, Thirlby R, Wu C. Efficacy of continuous wound catheter delivering local anesthetic for postoperative analgesia: A quantitative and qualitative systematic review of randomized controlled trials. J Am Coll Surg. 2006; 203(6):914-32. 